\title{
ECO-FRIENDLY MATERIAL FOR PACKAGING
}

\author{
Laura Gegeckienè, Ingrida Venyte \\ Kaunas University of Technology, Faculty of Mechanical Engineering and Design, Department \\ of production engineering, Kaunas, Lithuania
}

\begin{abstract}
At the moment there exists a predominant prevalence of the combined packaging (i. e. cardboard is covered with polyethylene) in the food packaging market, which provides the necessary barrier properties for a packaged product. However, there also exist a great number of problems regarding the issue such as packaging sorting, recycling, waste management, and economic losses. According to the latest data, 65 enterprises in Lithuania are currently working in the recycling industry. They can recycle different types of packaging.

The issue of ecology is highly relevant in the printing industry. It is not a secret that the global population is growing rapidly. As the demand for food and non-food product packaging increases, the production volume increases accordingly. In the future, it is expected that the volume of packaging production will increase accordingly. MMK cardboard can be called a revolution in the industry of packaging. Until now, packaging which has direct contact with food must be laminated with films such as PE. Plastic waste is one of the most common types of waste that takes a very long time to decompose. Normally, plastic packaging can take up to several hundred years to decompose in landfills, while cardboard is easily recyclable and takes up to half a year to biodegrade.

The aim of this research is to investigate the physical and mechanical properties and characteristics (in order to offer analog materials in the perspective) of the new materials with the necessary properties and compared to the properties of the most using materials.
\end{abstract}

Key words: environmentally friendly, MMK cardboard, force

\section{INTRODUCTION}

Water and air pollution have reached critical levels in much of the world's cities. Consequently, the chemicals in question are intensively depleting the ozone layer of our planet. Thanks to the scientists and the efforts of environmentally friendly institutions, the public is educated and encouraged to nurture nature, to understand its importance and potential threats. In the face of increasing education and human soprano about the importance of ecology, it can be assumed that people will pay even more attention in the future organic materials, for example, will choose a product that will be labeled as biodegradable packaging. In this case, the label that decomposes in an extremely fast time, instead of standard labels/packaging with a decomposes time of even a few hundred years.

\section{METHODS}

MMK cardboard was developed in late April 2016 in Frohnleiten, Austria (MMK, 2020). The main essence of this packaging material is to maintain different types of barrier properties.

The experimental investigation of bending was chosen for that to understand which cardboard as a raw material has the highest resistance on bending fatigue and also that to compare MMK cardboard mechanical properties to other most frequently used cardboard in the packaging industry. The following cardboard samples were compared to each other:

- $\quad$ MMK cardboard $305 \mathrm{gr} / \mathrm{m}^{2}$;

- ARKTIKA cardboard $305 \mathrm{gr} / \mathrm{m}^{2}$ - it is GC1 grade cardboard with multiple structures and a double coating on the topside and one layer of coating on the backside, and is printable on both sides (Arktika cardboard characteristics, 2020).

- Ensocoat cardboard $305 \mathrm{gr} / \mathrm{m}^{2}$ - one side fully coated board with a light coating on the reverse. Ensocoat has a strong bleached chemical pulp in a multiply structure (Ensocoat cardboard characteristics, 2020).

- Korsnäs White cardboard $305 \mathrm{gr} / \mathrm{m}^{2}$ - it is coated cardboard and made out of $100 \%$ virgin fiber (double-coated on the top side and single-coated on the reverse side) (Korsnäs White cardboard characteristics, 2020). 
The crushing test was performed using a Tinius Olsen H10KT electromechanical device for testing samples of rubber, metal, plastic, textile, cardboard, and other materials. In the experimental study, 5 samples were used in one sample group. All samples from these packages were acclimatized to $20 \pm 1^{\circ} \mathrm{C}$ for at least 24 hours prior to the test temperature and $50 \pm 3 \%$ humidity. Compression speed $12.5 \mathrm{~mm} / \mathrm{s}$. For packaging with static load, two identical dimensions and liners were chosen:

- MMK cardboard packaging (without barrier properties), $305 \mathrm{gr} / \mathrm{m}^{2}$, dimensions: 7x7x9 cm;

- $\quad$ ARKTIKA cardboard packaging, $305 \mathrm{gr} / \mathrm{m}^{2}$, dimensions: 7x7x9 cm.

\section{RESULTS}

Table 1: Results of the experimental investigation on bending fatigue

\begin{tabular}{|c|c|c|c|c|}
\hline No. & $\begin{array}{c}\text { Name of the } \\
\text { cardboard }\end{array}$ & $\begin{array}{c}\text { Grammage, } \\
\mathrm{g} / \mathrm{m}^{2}\end{array}$ & $\begin{array}{c}\text { Average number of cycles } \\
\text { (longitudinal direction of } \\
\text { the fibers) }\end{array}$ & $\begin{array}{c}\text { Average number of cycles } \\
\text { (transverse direction of fibers) }\end{array}$ \\
\hline 1. & MMK & 305 & 77 & 56 \\
\hline 2. & Arktika & 305 & 1261 & 990 \\
\hline 3. & Ensocoat & 305 & 4211 & 3837 \\
\hline 4. & Korsnäs White & 305 & 3071 & 2785 \\
\hline
\end{tabular}

From the study, we can conclude that the samples cut in the machine direction (MD) of the fibers are on average $12 \%$ stronger than the cross direction (CD) and withstand a higher number of bending cycles. This is because specimens that are cut in the CD direction of the fiber are bent parallel to the fibers, so they break faster.

The dependences of the compressive strength of MMK packaging are shown in Figure 1.

\section{MMK carton static load compressive strength dependencies}

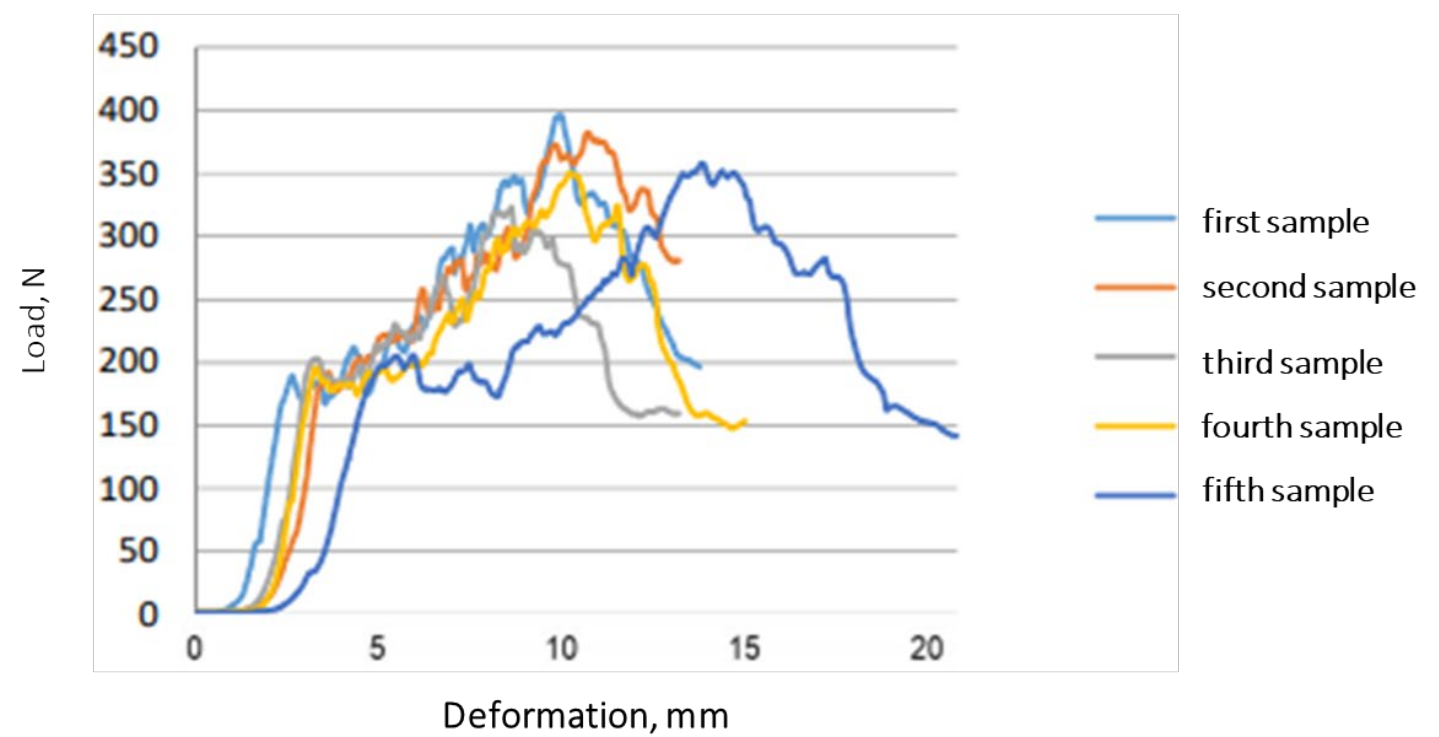

Figure 1: MMK carton static load compressive strength dependencies

As we can see from the graph for all five analyzed packaging results are similar. Initial deformation for MMK carton was observed when $F_{\text {critical }}=195.6 \mathrm{~N}$ (19.56 KG). 
The dependences of the compressive strength of ARKTIKA packaging are shown in Figure 2.

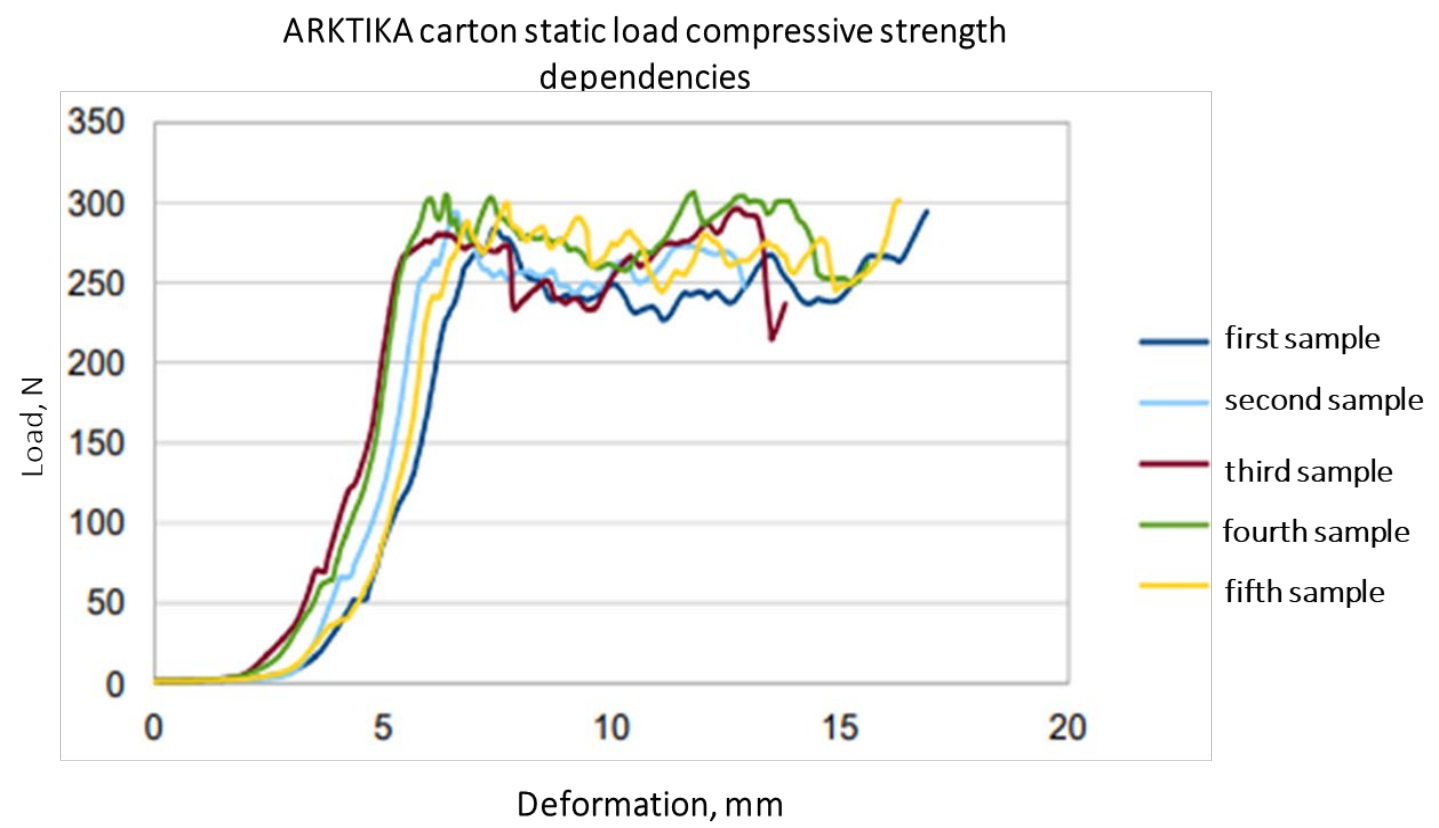

Figure 2: ARKTIKA carton static load compressive strength dependencies

As we can see from the graph, all five ARKTIKA analyzed packaging showed similar experiment results. The initial deformation was observed when $F_{\text {critical }}=300 \mathrm{~N}(30.00 \mathrm{KG})$.

Comparative static load compression strength dependencies are shown in Figure 3.

\section{Comparative static load compression strength dependencies}

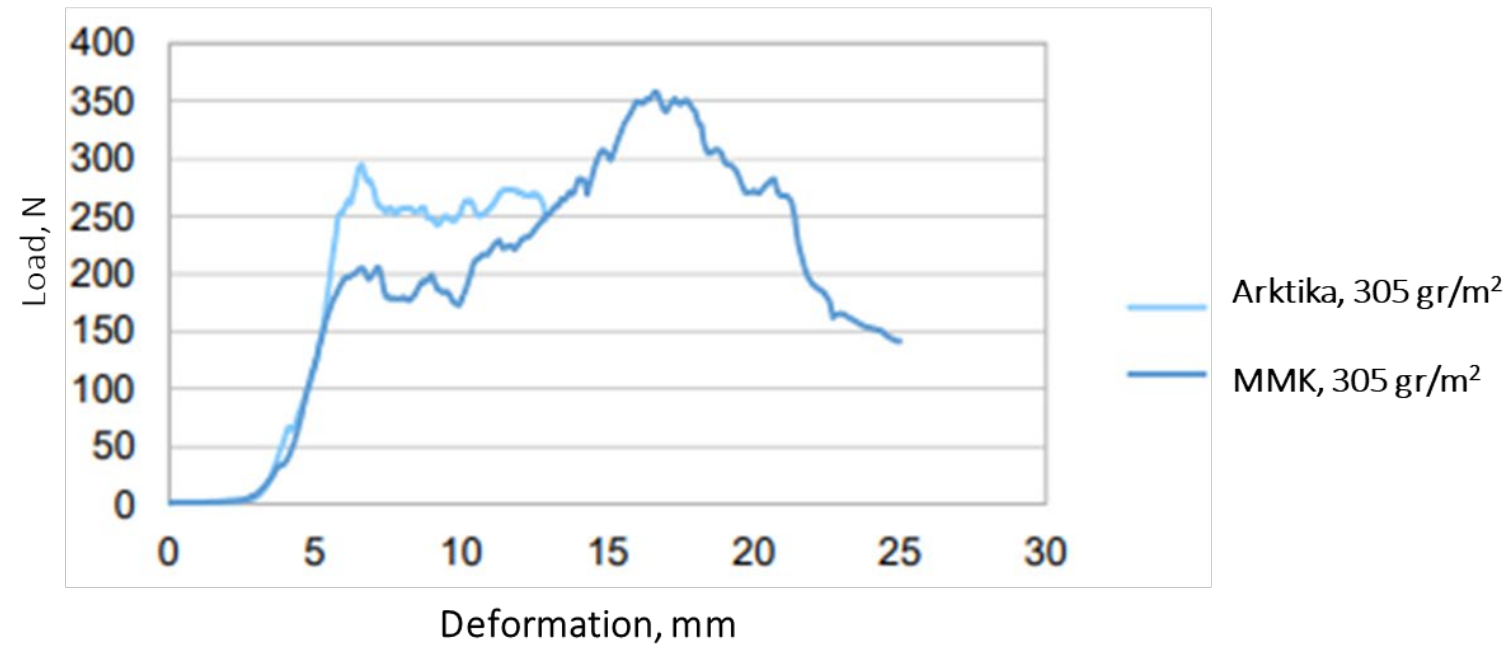

Figure 3: MMK and ARKTIKA carton static load compressive strength dependencies

After performing a crushing test the same size packages, we can conclude that MMK cardboard is less resistant than one of the main packaging raw materials - ARKTIKA cardboard. The graphs show that MMK cardboard can withstand 104.4 N (10.44 kg) less load than ARKTIKA cardboard. 


\section{CONCLUSIONS AND DISCUSIONS}

From the mechanical compression and bending experimental results, we can clearly see that the mechanical effect of the biodegradable MMK cardboard is weaker than the other ordinary materials using in the packaging industry. Decreased strength was shown in the bending test ( 30 times less resistant than other specimens) and the crushing test ( $10 \mathrm{~kg}$ less resistant to load).

However, it is worth considering the growing ecological problem. Primary food packaging that does not require additional PP coating and is biodegradable is better than now ordinary using packaging with PP. And analyzed packaging's are suitable for light products and results show that the critical force it's enough the strength of these types of packaging.

An ecological solution to start using MMK cardboard as a raw material for food packaging would raise the company's reputation vis-à-vis customers and direct competitors, and the company could call itself an environmental organization and thus attract new customers.

\section{REFERENCES}

[1] Arktika cardboard characteristics, URL: https://www.budak.com.tr/upload/specs-international-paper-sun-arktika.pdf (last request: 2020-08-12.).

[2] Ensocoat cardboard characteristics, URL: https://www.paper.co.uk/PremierPaper/media/Graphical-Board/Ensocoat.pdf (last request: 2020-07-15.).

[3] Korsnäs White cardboard characteristics, URL: https://www.antalis.no/mediashare/g4media/pdf/PE_EN_Korsnas_White_EXP_31122013_00.pdf (last request: 2020-07-15.).

[4] MMK cardboard, URL: https://www.mm-karton.com/en/produkte/foodboardtm/ (last request: 2020-08-17.).

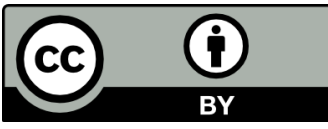

(C) 2020 Authors. Published by the University of Novi Sad, Faculty of Technical Sciences, Department of Graphic Engineering and Design. This article is an open access article distributed under the terms and conditions of the Creative Commons Attribution license 3.0 Serbia (http://creativecommons.org/licenses/by/3.0/rs/). 